\title{
A PHD Finger Motif in the C Terminus of RAG2 Modulates Recombination Activity
}

\section{Citation}

Elkin, Sheryl K., Dmitri Ivanov, Mark Ewalt, Colin G. Ferguson, Sven G. Hyberts, Zhen-Yu J. Sun, Glenn D. Prestwich, et al. 2005. "A PHD Finger Motif in the C Terminus of RAG2 Modulates Recombination Activity." Journal of Biological Chemistry 280 (31): 28701-10. https:// doi.org/10.1074/jbc.m504731200.

\section{Permanent link}

http://nrs.harvard.edu/urn-3:HUL.InstRepos:41483495

\section{Terms of Use}

This article was downloaded from Harvard University's DASH repository, and is made available under the terms and conditions applicable to Other Posted Material, as set forth at http:// nrs.harvard.edu/urn-3:HUL.InstRepos:dash.current.terms-of-use\#LAA

\section{Share Your Story}

The Harvard community has made this article openly available. Please share how this access benefits you. Submit a story.

Accessibility 


\title{
A PHD Finger Motif in the C Terminus of RAG2 Modulates Recombination Activity*[ $₫$
}

Received for publication, April 29, 2005, and in revised form, June 15, 2005

Published, JBC Papers in Press, June 17, 2005, DOI 10.1074/jbc.M504731200

\begin{abstract}
Sheryl K. Elkin, ${ }^{a, b}$ Dmitri Ivanov, ${ }^{b, c}$ Mark Ewalt, ${ }^{b, d, e}$ Colin G. Ferguson, ${ }^{,}$Sven G. Hyberts, ${ }^{c}$ Zhen-Yu J. Sun, ${ }^{c}$ Glenn D. Prestwich, ${ }^{g}$ Junying Yuan, ${ }^{d}$ Gerhard Wagner, ${ }^{c, h}$ Marjorie A. Oettinger, ${ }^{a, i}$ and Or P. Gozani ${ }^{d, e, j}$

From the ${ }^{a}$ Department of Molecular Biology, Massachusetts General Hospital, Boston, Massachusetts 02114, the ${ }^{c}$ Department of Biological Chemistry and Molecular Pharmacology, Harvard Medical School, Boston, Massachusetts 02115, the ${ }^{d}$ Department of Cell Biology, Harvard Medical School, Boston, Massachusetts 02115, ${ }^{f}$ Echelon Biosciences, Inc., Salt Lake City, Utah 84108, the ${ }^{g}$ Department of Medicinal Chemistry, the University of Utah, Salt Lake City, Utah 84108, and the ${ }^{e}$ Department of Biological Sciences, Stanford University, Stanford, California 94305
\end{abstract}

The RAG1 and RAG2 proteins catalyze V(D)J recombination and are essential for generation of the diverse repertoire of antigen receptor genes and effective immune responses. RAG2 is composed of a "core" domain that is required for the recombination reaction and a C-terminal nonessential or "non-core" region. Recent evidence has emerged arguing that the non-core region plays a critical regulatory role in the recombination reaction, and mutations in this region have been identified in patients with immunodeficiencies. Here we present the first structural data for the RAG2 protein, using NMR spectroscopy to demonstrate that the $C$ terminus of RAG2 contains a noncanonical PHD finger. All of the non-core mutations of RAG2 that are implicated in the development of immunodeficiencies are located within the PHD finger, at either zinc-coordinating residues or residues adjacent to an $\alpha$-helix on the surface of the domain that participates in binding to the signaling molecules, phosphoinositides. Functional analysis of disease and phosphoinositide-binding mutations reveals novel intramolecular interactions within the noncore region and suggests that the PHD finger adopts two distinct states. We propose a model in which the equilibrium between these states modulates recombination activity. Together, these data identify the PHD finger as a novel and functionally important domain of RAG2.

During immune system development, immunoglobulin and $\mathrm{T}$ cell receptor genes are assembled from their component gene segments. This process, called V(D)J recombination, is initi-

* This work was supported in part by National Institutes of Health Grants RO1 GM48026 (to M. A. O.), RO1 AI37587 (to G. W.), RO1 AG16674 (to J. Y.), RO1 NS29632 (to G. D. P.), and R44 GM065683 (to C. G. F.). The costs of publication of this article were defrayed in part by the payment of page charges. This article must therefore be hereby marked "advertisement" in accordance with 18 U.S.C. Section 1734 solely to indicate this fact.

S The on-line version of this article (available at http://www.jbc.org) contains Fig. S1.

${ }^{b}$ These authors contributed equally to this work

${ }^{h}$ To whom correspondence may be addressed. E-mail: gerhard wagner@hms.harvard.edu.

${ }^{i}$ To whom correspondence may be addressed. E-mail: oettinger@ frodo.mgh.harvard.edu.

${ }^{j}$ Supported by NIA, National Institutes of Health Grant KO8AG19245 and is a recipient of a Burroughs Wellcome Career Development Award in Biomedical Sciences.To whom correspondence may be addressed: Dept. of Biological Sciences, Stanford University, Stanford, CA 94305. Tel.: 650-736-7639; Fax: 650-725-8309; E-mail: ogozani@stanford.edu. ated by the lymphoid-specific recombination activating genes 1 and 2 (RAG1 and RAG2) $(1,2)$. The RAG proteins recognize and bind recombination signal sequences flanking each coding segment and introduce double-strand DNA breaks, which are subsequently resolved into coding joints and signal joints. Processing and joining of the ends require the activity of the ubiquitously expressed proteins from the nonhomologous end joining pathway of DNA repair (reviewed in Ref. 3). V(D)J recombination is critical for proper immune system function; accordingly, mutations in the RAG or nonhomologous end joining proteins result in immunodeficiencies, and inappropriate RAG activity can lead to genomic instability and cancer $(4,5)$.

RAG2 can be divided into two functionally defined regions, an N-terminal "core" domain (amino acids 1-383) and a Cterminal "non-core" domain (amino acids 384-527) (see Fig. $1 A$ ). The core domain is necessary and sufficient for carrying out $\mathrm{V}(\mathrm{D}) \mathrm{J}$ recombination in vivo on exogenous plasmid substrates $(6,7)$, as well as $\mathrm{V}(\mathrm{D}) \mathrm{J}$ cleavage in vitro (8). The noncore domain is dispensable for activity in both of these assays; however, its high conservation throughout evolution suggests it serves critical functions. Indeed, replacement of the endogenous $R A G 2$ gene with only the core domain results in impaired development of $\mathrm{B}$ and $\mathrm{T}$ cells in mice $(9,10)$. Moreover, recent studies have implicated the $\mathrm{C}$ terminus of RAG2 in the restriction of RAG1/2-mediated transposition (11-13) as well as a nonstandard outcome of $\mathrm{V}(\mathrm{D}) \mathrm{J}$ recombination, hybrid joint formation (14). Finally, mutations within the RAG2 C terminus are linked to the pathogenesis of severe combined immunodeficiency (SCID) ${ }^{1}$ and Omenn syndrome (OS) (15-18).

Two specific activities encoded within the non-core domain have been identified, a nuclear localization signal and a degradation signal $(19,20)$. However, the amino acids mutated in SCID and OS do not overlap with the nuclear localization signal or degradation signals. Rather, these mutations are found within a region of the $\mathrm{C}$ terminus of RAG2 that was predicted by its primary amino acid sequence to be a PHD finger-like motif (21), although protein-motif predicting programs such as Pfam and Swiss-Prot do not detect a PHD finger within this region under low stringencies (data not shown).

The PHD finger motif is present throughout eukaryotic proteomes, most often on chromatin-associated proteins (22).

\footnotetext{
${ }^{1}$ The abbreviations used are: SCID, severe combined immunodeficiency; OS, Omenn syndrome; PtdIns, phosphoinositides; WT, wild type; aa, amino acids; GST, glutathione $S$-transferase; NOE, nuclear Overhauser effect; NOESY, nuclear Overhauser effect spectroscopy; IPs, inositol polyphosphates; PIP, phosphatidylinositol phosphate; E3, ubiquitin-protein isopeptide ligase.
} 


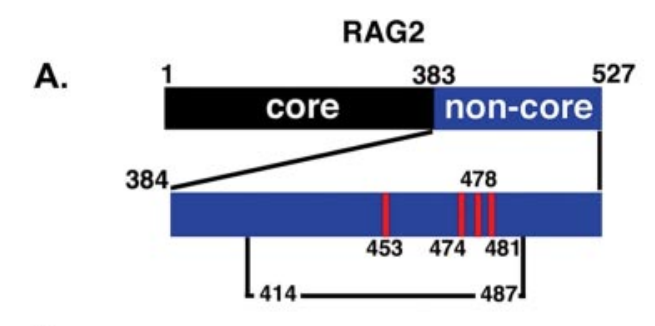

FIG. 1. The RAG2 $\mathrm{C}$ terminus contains a zinc finger. $A$, schematic of the RAG2 protein. Black, RAG2 core region (aa 1-383); blue, non-core region (aa 384527). The segment used for NMR structure determination (aa 414-487) is marked. Red bars represent residues mutated in OS or SCID patients: 453 , W453R; 474, N474S; 478, C478Y; 481, H481P. $B$, family of the 20 lowest energy NMR structures. Cross-eye stereo diagram showing the protein backbone and the zinc-coordinating residues. Red spheres, zinc atoms $\mathrm{Zn} 1$ and $\mathrm{Zn} 2$.
B.

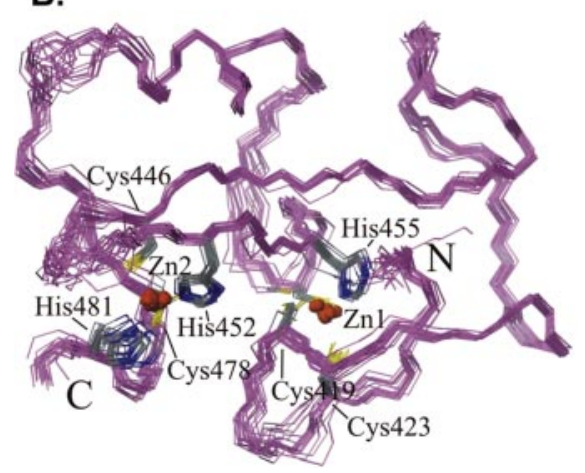

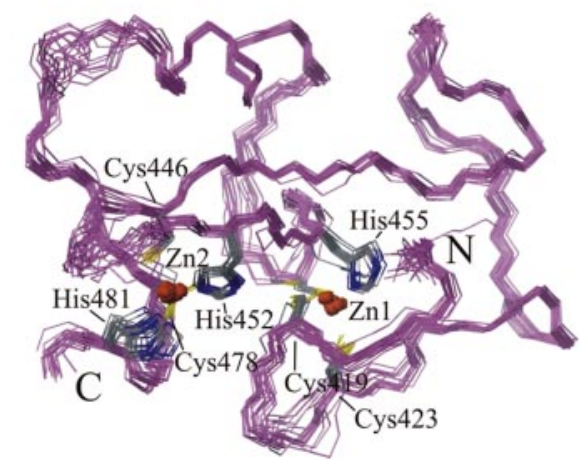

Structurally, the PHD finger, like the related FYVE and RING finger modules, belongs to the treble class of zinc-binding domains $(23,24)$. The FYVE finger is a well characterized PtdInsP-binding module, and RING fingers function as components of E3 ubiquitin ligase enzymes (reviewed in Refs. 25 and 26 ). Both of these functions have been reported for PHD fingers from different proteins $(27,28)$, although recent analyses argue that PHD fingers with E3 ubiquitin ligase activity are more likely to be RING finger variants $(29,30)$. In addition, two recent studies $(31,32)$ describe $\mathrm{PHD}$ finger interactions with nucleosomes.

Structural information about the RAG proteins has long been sought, in hope that it would lend insight into the biochemistry and regulation of $\mathrm{V}(\mathrm{D}) \mathrm{J}$ recombination. In this study, we present the first structural data for the RAG2 protein, demonstrating that the $\mathrm{C}$ terminus of RAG2 contains a noncanonical PHD finger. We find that this module directly interacts with PtdInsPs, and mutations that disrupt this binding or cause immunodeficiency can be shown to alter the recombination activity of RAG2. Thus, we identify the PHD finger as a novel and functionally important domain of RAG2.

\section{MATERIALS AND METHODS}

NMR Studies and Homology Modeling-Murine Rag2 protein (residues 414-487) in buffer (20 mm Tris, $\mathrm{pH} 7.2,50 \mu \mathrm{M} \mathrm{ZnSO}, 13 \mathrm{~mm}$ $\beta$-mercaptoethanol) was used for the NMR studies. Three pairs of triple resonance experiments $\mathrm{HNCA} / \mathrm{HN}(\mathrm{CO}) \mathrm{CA}, \mathrm{HN}(\mathrm{CA}) \mathrm{CB} / \mathrm{HN}(\mathrm{COCA}) \mathrm{CB}$, $\mathrm{HNCO} / \mathrm{HN}(\mathrm{CA}) \mathrm{CO}$ were collected by using uniformly ${ }^{15} \mathrm{~N}-,{ }^{13} \mathrm{C}-$, and ${ }^{2} \mathrm{H}$-labeled protein. The backbone assignments were obtained with the automatic assignment program Ibis (33) and side chain assignments with $\mathrm{HC}(\mathrm{C}) \mathrm{H}, \mathrm{H}(\mathrm{CCO}) \mathrm{NH}$, and $\mathrm{C}(\mathrm{CO}) \mathrm{NH}$ Tocsy experiments. Virtually complete backbone and side chain assignments were achieved. Distance restraints for structure calculations were obtained from ${ }^{15} \mathrm{~N}$ NOESYHSQC ${ }^{13} \mathrm{C}$ NOESY-HSQC, and two-dimensional NOESY experiments. NMR data were processed with NMRPipe (34) and spectral analysis and assignments with Xeasy. Initial structures were obtained using the molecular structure and molecular dynamics package DYANA (35) with no zinc coordination constraints. The 20 lowest energy structures of 100 total structures calculated were used as starting points for energy minimization calculations using Xplor-NIH (36). Zinc atoms and additional distance and angle constraints were incorporated at this stage to maintain the canonical tetrahedral geometry of the metal sites.

Recombinant Protein Expression-GST fusion proteins were purified as described previously (28). Full-length RAG2 and all RAG2 derivatives were cloned into p3xFLAG-CMV vector (Sigma), expressed in $293 \mathrm{~T}$ cells, and dialyzed overnight into storage buffer $(150 \mathrm{mM} \mathrm{KCl}$, $25 \mathrm{~mm}$ HEPES, $\mathrm{pH} 7.5,20 \%$ glycerol, $2 \mathrm{~mm}$ dithiothreitol). In vitro translation of proteins was carried out per the manufacturer's instructions (Promega).

PtdInsP Binding Assays-Protein-lipid blots and PtdInsP affinity resin pull-downs were performed as described (28). Liposome pull-down assays were carried out essentially as described (37). Briefly, $1 \mu \mathrm{g}$ of protein, $20 \mu \mathrm{l}$ of $1 \mathrm{~mm}$ PolyPIPosomes ${ }^{\mathrm{TM}}$ (Echelon Biosciences), and $1 \mathrm{ml}$ of binding buffer (50 mu Tris, $\mathrm{pH} 7.5,150 \mathrm{~mm} \mathrm{NaCl}, 0.05 \%$ Nonidet $\mathrm{P}-40$ ) were rotated for $10 \mathrm{~min}$ at room temperature and centrifuged at 13,000 rpm for $10 \mathrm{~min}$. Liposome pellet was resuspended in $1 \mathrm{ml}$ of binding buffer and then centrifuged. This step was repeated three times, and the bound and flow-through samples (at a relative ratio of 3:1) were resolved by SDS-PAGE, and GST fusion proteins were detected by Western analysis using anti-GST antibody (Amersham Biosciences).

In Vivo and in Vitro Recombination Assays-In vivo V(D)J recombination assays were performed as described previously (38) with BR3neo cells, and the plasmids pGG49 (signal joints) and pGG51 (coding joints) were used as reporters $(39,40)$. Full-length RAG1 was expressed using the M2CD7 plasmid (7). RAG2 and derivatives were transiently expressed using the p3xFLAG-CMV vector (Sigma). Expression of all proteins was confirmed by Western analysis with anti-FLAG antibody of FLAG-IPs (Sigma). FLAG-tagged RAG2 and derivatives (purified three times) were used for in vitro cleavage and transposition assays as described previously (11).

\section{RESULTS}

Solution Structure of the RAG2 C Terminus Reveals the Presence of a PHD Finger Module-To determine directly whether the RAG2 non-core region contains a zinc finger module, the structure of RAG2 from amino acids 414 to 487 (Fig. $1 A$ ) was solved using solution NMR spectroscopy (Fig. $1 B$; structural statistics are shown in Table I). The protein construct encompasses an independently folded protein domain, and the spectral changes induced by EDTA treatment indicate that zinc is required for proper folding and structural stability of the domain (data not shown).

To identify experimentally the zinc-ligating residues, initial structure calculations were performed with no assumptions made about zinc coordination. The NOE contacts and the $\mathrm{C} \beta$ chemical shifts were sufficient to unambiguously identify Cys419, Cys-423, Cys-446, Cys-458, and Cys-478 as zinc-coordinating residues (Fig. $1 B$; Table I). In the RAG2 sequence, cysteines are not positioned to occupy the 4th, 5 th, and 8th zinc-binding position, but a number of histidine residues are appropriately located to be reasonable candidates (21). Using ${ }^{15} \mathrm{~N}$ HSQC analysis of the histidine side chain signals in combination with ${ }^{111} \mathrm{Cd}$ metal substitution, we identified His-452, His-455, and 
TABLE I

NMR structure determination statistics

Structured residues ${ }^{a}$

68

$\langle$ r.m.s.d. $\rangle$ from mean structure ${ }^{a}$ backbone/heavy atom $(\AA)$

Total NOE distance constraints

Short range (0-1)

Medium range (2-4)

Long range $(>4)$

Hydrogen bonds

Dihedral angles

$\mathrm{Zn}^{2+}$ constraints

Ramachandron plot (\%)

Most favorable region

Additionally allowed region

Generously allowed region

Disallowed region

\section{$0.60 / 1.01$}

943

606

80

257

12

53

21

63.8

34.5

1.5

0.2

${ }^{a}$ Residues 415-482 of RAG2. r.m.s.d. indicates root mean square deviation. All values were based on the ensemble of 20 lowest energy structures.

His-481 as zinc-coordinating residues (supplemental Fig. 1). Thus, overall, two zinc ions are bound in the RAG2 C-terminal zinc finger by residues Cys-419, Cys-423, Cys-446, His-452(N$\epsilon 2)$, His-455(N- $\delta 1)$, Cys-458, Cys-478, and His-481(N- $\delta 1)$ in the characteristic interleaved topology that is shared by $\mathrm{PHD}$, RING, and FYVE finger modules (Fig. $1 B$ and Fig. $2 B$ ).

The ${ }^{111} \mathrm{Cd}$ substitution experiments revealed that $\mathrm{Zn} 1$ is easily substituted during EDTA treatment, whereas Zn2 substitution requires longer EDTA treatment and higher temperatures, indicating that the RAG2 zinc finger has higher affinity for $\mathrm{Zn} 2$ than $\mathrm{Zn} 1$ (supplemental Fig. 1). Notably, mutations in the Zn2-coordinating residues, Cys-478 and His-481, are found in SCID, suggesting that zinc coordination and integrity of the PHD finger fold is critical for the function of RAG2 (Fig. 1A) (17).

PHD, FYVE, and RING finger modules all contain two zinc ions separated by $\sim 14 \AA$ with two strands of distorted $\beta$-sheet connecting the two metal centers (Fig. 2) (23, 41-43). The Cterminal zinc finger of RAG2 has the same topology and clearly belongs in the same structural class. The hydrophobic core and metal coordination geometry in the RAG2 structure contains the characteristic features of the PHD finger module, despite the differences in specific zinc-coordinating residues (Fig. 2A). First, as in other PHD fingers, a histidine ligand of Zn1 (His-455) forms part of the hydrophobic core of the protein (Fig. 1B). This is confirmed by the slow exchange of the $\mathrm{H}-\epsilon 2$ proton, which makes it visible in ${ }^{15} \mathrm{~N}$ HSQC spectra, and numerous NOE contacts of the histidine side chain with other core residues (data not shown). In addition, the coordination of the second zinc is structurally similar to that of other PHD fingers, with two zincbinding residues (Fig. $2 B, C 446$ and H452) located on both sides of the $\beta$-turn $(23,24,44)$. This is in contrast to RING fingers, as those residues are shifted toward the second $\beta$-strand (43). Finally, the site of the third distorted $\beta$-strand C-terminal to the last zinc-binding residues typical of RING fingers is obstructed in RAG2 by the loop between the third and fourth zinc-binding pairs, again similar to what is observed for other PHD finger structures (Fig. $2 B$ ). We note that the L1 segment of RAG2 is considerably longer than the L1 segments of other known PHD finger structures (Fig. 2). The L2 segment of the RAG2 zinc finger contains an $\alpha$-helix (Fig. $2 B$ ) which, although not a common feature of PHD fingers, has been observed in a number of PHD finger structures recently deposited in the Protein Data Bank (codes 1WE9, 1WEM, 1WEP, and 1WEV). The packing of this helix is distinct from the packing of the correspondingly located helix in RING fingers (Fig. 2B). Based on these data and consistent with predictions of the primary sequence (21), we conclude that the zinc finger contained within the RAG2 C terminus is a noncanonical PHD finger.
The RAG2 C Terminus Interacts with PtdInsPs-Two functions associated with PHD fingers are PtdInsP binding and E3 ubiquitin ligase activity $(27,28)$. We have not detected the latter activity for RAG2 (data not shown). To test if RAG2 binds PtdInsPs, protein-lipid blot assays (Fig. $3 A$ ) were carried out using in vitro translated full-length RAG2 and core RAG2 (named Core, aa 1-383), which lacks the PHD finger (Fig. 1A). Full-length RAG2, but not Core, bound to the phosphorylated PtdInsP species (Fig. 3B). Similarly, in an independent assay, in vitro translated RAG2, but not Core, bound to PtdInsPcoupled affinity resins (Fig. $3 C$ ). These data suggest that RAG2 can bind to PtdInsPs and that the non-core region of RAG2 is required for this activity.

To test directly whether the non-core region binds PtdInsPs, GST-RAG2 C-terminal fusion proteins were assayed for PtdInsP binding in lipid blot (Fig. $3 D$ ) or liposome pull-down (Fig. 3E (45)) assays. A C-terminal RAG2 construct containing the PHD finger and a downstream cluster of positively charged residues (RAG2-PHD-CT, aa 414-527) bound PtdInsPs robustly in both assays (Fig. 3, $D$ and $E$ ). RAG2-PHD-CT protein bound most strongly to bis-phosphorylated PtdInsPs in the lipid blot overlay assay (Fig. $3 D$ ) and to $\operatorname{PtdIns}(4,5) \mathrm{P}_{2}$ in the liposome pull-down assay (Fig. $3 E$ ). This binding profile is distinct from other PHD fingers tested to date, which characteristically bind preferentially to mono-phosphorylated PtdInsPs (Fig. 3, $D$ and $E$ ) (28). Notably, chelation of zinc by EDTA, which disrupts the structure of the RAG2 PHD finger, eliminated PtdInsP binding (Fig. 3D). Unfortunately, the RAG2PHD-CT aggregates at high protein concentrations, making it unsuitable for NMR structural studies. The RAG2 PHD finger domain alone (RAG2-PHD, aa 414-487), which was used in the structural studies, did not bind to PtdInsPs, and the C-terminal region alone (RAG2-CT, aa 488-527) bound weakly (Fig. $3 D$ ). Thus, RAG2-PHD-CT, encompassing both the PHD finger and the C-terminal basic patch, is necessary and sufficient for efficient PtdInsP binding.

Structural Model of RAG2 PHD Finger-PtdInsP Interactions-To gain insight into the structural basis of PtdInsPRAG2-PHD-CT interactions, the structure of the RAG2 PHD finger was superimposed onto the known structure of the FYVE finger-PtdIns(3)P complex (Fig. 4A) (46). This analysis revealed that a molecular surface of the RAG2 PHD finger, consisting of the L2 $\alpha$-helix and largely formed by the segment of the polypeptide chain between residues 462 and 474, aligns with the PtdInsP-binding surface of the FYVE finger (Fig. 4A). Considering the importance of positive charge for binding to the acidic head group of PtdInsPs (47), two residues within this region of RAG2, Arg-464 and His-468, are probable participants in PtdInsP recognition (Fig. 4B). Moreover, residues mutated in patients with OS and SCID (Trp-453 and Asn-474, respectively) are adjacently located and predicted to affect this surface area (Fig. 4B). An analogous segment in the ING2 PHD finger contains a basic patch formed by three lysine residues that are necessary for efficient PtdInsP binding by ING2 as well as its pro-apoptotic activity (Fig. 4C) (28). Notably, the contacts formed by this surface alone, however, are not sufficient for PtdInsP binding for either RAG2 or ING2, as both absolutely require residues located $\mathrm{C}$-terminal to the core $\mathrm{PHD}$ finger structure (Fig. $4 C$ and see Fig. $3 D$ ). Thus, it is likely that the structural basis of RAG2 PHD finger interactions with PtdInsPs is mechanistically analogous to that of other PHD finger proteins.

Functional Analysis of the RAG2 PHD Finger-Although most of the mutations that lead to SCID and OS have been mapped to the core regions of RAG1 and RAG2, several mutations are found within the PHD finger of RAG2 (Fig. 4B), 

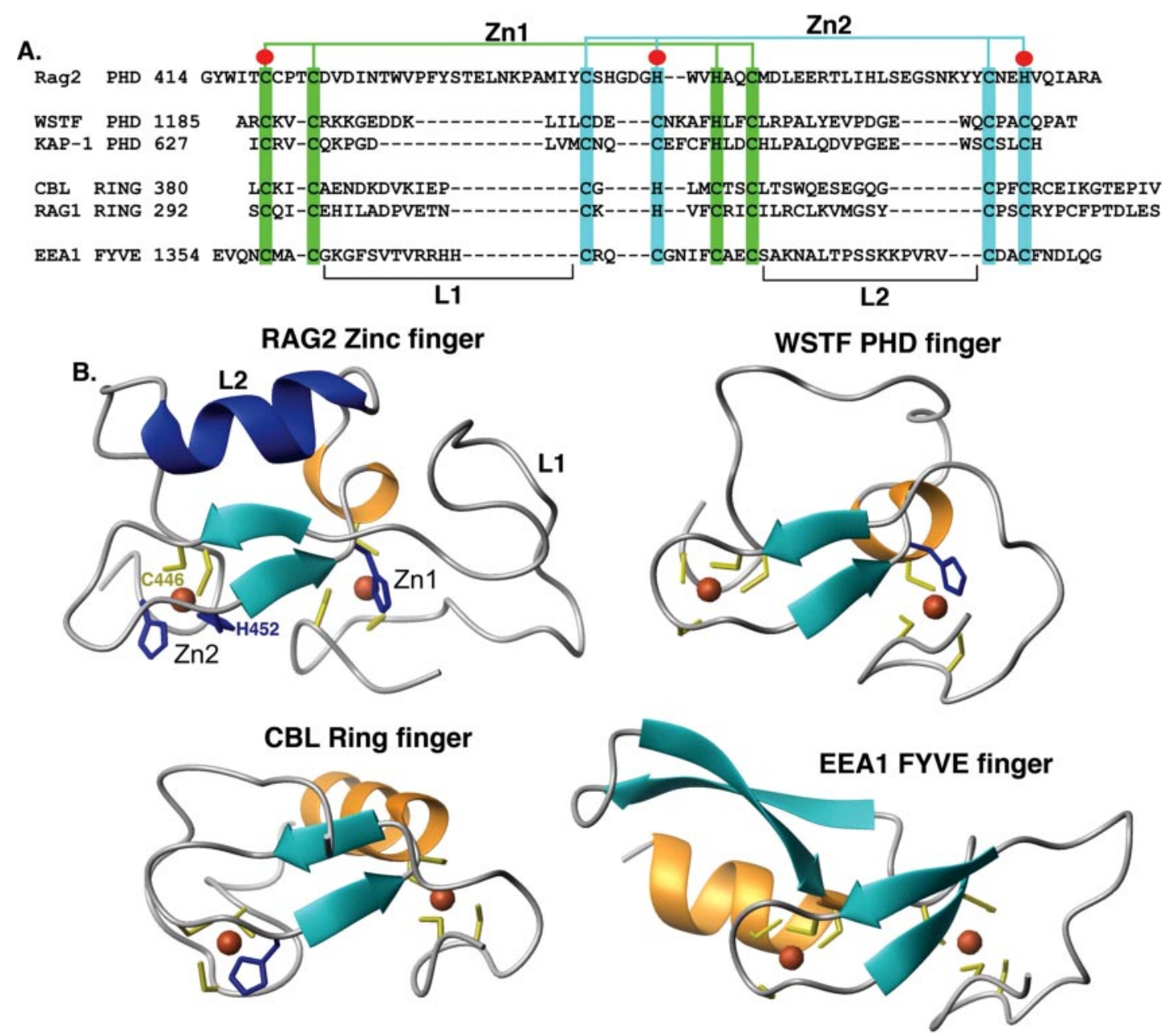

FIg. 2. The RAG2 C terminus contains a noncanonical PHD finger. A, alignment of the RAG2 zinc finger to representative zinc fingers from similar structural classes. The RAG2 sequence (aa 414-487) was aligned to the indicated PHD, RING, and FYVE finger sequences. Red circles represent zinc-binding residues Cys-419, His-452, and His-481 of RAG2 that deviate from the PHD finger consensus. Zn1, first zinc; $Z n 2$, second zinc; $L 1$ and $L 2$, extended segments of sequence between pairs of zinc-coordinating residues. $B$, the RAG2 zinc finger is structurally most similar to the PHD finger. Ribbon schematics compare the C-terminal zinc finger of RAG2 to the indicated PHD, RING, and FIVE fingers. The ligands of the two zinc ions appear as interleaved pairs in the primary sequence of these proteins as shown in $A$. Two extended polypeptide segments $(L 1$ and $L 2$, see $A$ ) separate equivalent pairs of zinc-coordinating residues. The $L 1$ segment contains the first strand of the conserved $\beta$-sheet, whereas the conformation of L2 varies significantly between different proteins. The four domains are oriented in the same way using conserved $\beta$-sheet and zinc ions as structural reference. The L2 $\alpha$-helix of RAG2 is denoted in blue. Yellow, zinc-coordinating cysteine residues; blue, zinc-coordinating histidine residues; red spheres, zinc atoms.

suggesting that integrity of this domain might be critical for normal RAG2 function. To test this hypothesis, a structurebased mutational analysis was carried out to identify PHD finger mutants defective for PtdInsP binding, and the ability of these mutants to execute recombination in vivo was determined.

First, to quantify the relative affinity of RAG2 PHD finger derivatives for PtdInsPs, protein-lipid blot overlays were carried out using lipid blots containing serial dilutions of PtdIns $(4,5) \mathrm{P}_{2}$. As shown in Fig. $5 A$, at as little as 2.5 pmol, wild-type RAG2-PHD-CT and phospholipase $\mathrm{C} \delta$-PH detect PtdIns $(4,5) \mathrm{P}_{2}$. In contrast, p40-PX, FAPP1-PH, and GST alone bound very weakly or not at all (Fig. $5 A$ ). Among the disease-associated mutants, $\mathrm{N} 474 \mathrm{~S}_{(\mathrm{PHD}-\mathrm{CT})}$ interacts with PtdIns $(4,5) \mathrm{P}_{2}$ at a level comparable with wild type, whereas $\mathrm{W}_{453 \mathrm{R}_{(\mathrm{PHD}-\mathrm{CT})}}$ and $\mathrm{C}_{478 \mathrm{~F}_{(\mathrm{PHD}-\mathrm{CT})}}$ displayed an $\sim 5$-fold reduction in binding, and $\mathrm{H} 481 \mathrm{P}_{\text {(PHD-CT) }}$ failed to bind (Fig. $5 B$ ).

The disease mutants were next tested in a transient $\mathrm{V}(\mathrm{D}) \mathrm{J}$ recombination assay to assess recombination frequencies in vivo. Each recombination assay was performed with full-length RAG1 as the partner protein, using an exogenous substrate to detect either signal joints or coding joints. We first established the recombination activity of full-length RAG2 (WT) in our system; all other constructs were then normalized to WT activity. Consistent with previous reports, Core displayed $\sim 20 \%$ activity in both signal and coding joint formation compared with WT (Fig. 5C) $(6,48)$. The N474S mutant carries out recombination at WT levels, consistent with the ability of N474S $\mathrm{S}_{\text {(PHD-CT) }}$ to bind PtdInsPs at WT levels (Fig. 5, $B$ and $C$ ). We note that manifestation of the defective phenotype associated with the N474S mutation might only be detectable in recombination at the endogenous loci, or alternatively, it is possible that these patients harbor an additional mutation that contributes to the immunodeficiency. The other three disease mutants all displayed severely reduced recombination frequencies (Fig. 5 C). The phenotype of the $\mathrm{C} 478 \mathrm{~F}$ and H481P mutations is most likely because of disruption in the structure of the protein, as these proteins were poorly expressed compared with WT, W453R, and N474S proteins (Fig. 5D). We note that all the proteins localized to the nucleus, with Core entering the nucleus in a RAG1-dependent manner (data not shown) (20).

Next, we investigated the effects of mutations predicted to disrupt interactions with PtdInsPs. First, a series of truncations eliminating progressively larger sections of the $\mathrm{C}$ termi- 


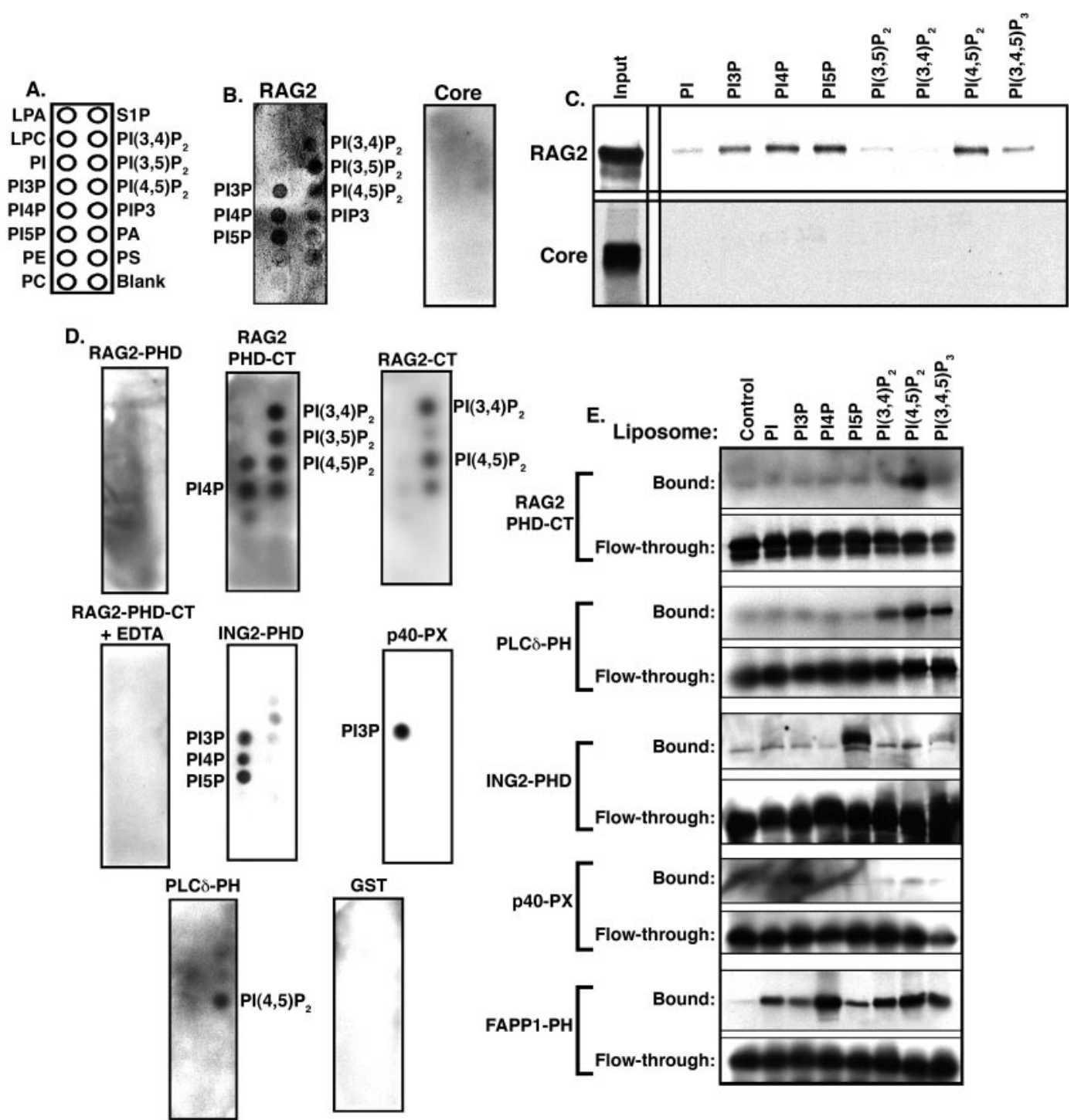

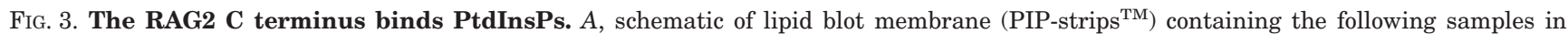
100-pmol spots: lysophosphatidic acid (LPA), lysophosphocholine (LPC), PtdIns (PI), PtdIns (3)P (PI3P), PtdIns(4)P (PI4P), PtdIns(5)P (PI5P), phosphatidylethanolamine $(P E)$, phosphatidylcholine $(P C)$, sphingosine 1-phosphate $(S 1 P), \operatorname{PtdIns}(3,4) \mathrm{P}_{2}\left(P I(3,4) P_{2}\right), P \operatorname{Ptd} I n s(3,5) \mathrm{P}_{2}\left(P I(3,5) P_{2}\right)$, PtdIns $(4,5) \mathrm{P}_{2}\left(P I(4,5) P_{2}\right), \operatorname{PtdIns}(3,4,5) \mathrm{P}_{3}\left(P I(3,4,5) P_{3}\right)$, phosphatidic acid $(P A)$, phosphatidylserine $(P S)$, and Blank. $B$, and $C$, full-length RAG2, but not core RAG2, interacts with PtdInsPs. $B$, autoradiograph of PIP-strips ${ }^{\mathrm{TM}}$ incubated with in vitro translated, ${ }^{35} \mathrm{~S}-$ labeled full-length RAG2 (left panel) or Core RAG2 (right panel). Labeled PtdInsPs indicate an interaction. C, autoradiograph of in vitro translated, ${ }^{35} \mathrm{~S}-\mathrm{labeled}$ RAG2 (top panel) and Core (bottom panel) proteins bound and eluted from the indicated PtdInsP-coupled affinity resins, resolved by SDS-PAGE. Input denotes 10\% of total in vitro translated protein in each assay. $D$ and $E$, amino acids $414-527$ of RAG2 bind to PtdInsPs. $0.5 \mu \mathrm{g} / \mathrm{ml}$ of the indicated GST fusion proteins: RAG2-PHD, aa 414-487; RAG2-PHD-CT, aa 414-527; RAG2-CT, aa 487-527; ING2-PHD, PHD finger of ING2 (binds PtdIns(5)P); $p 40-P X$, PX domain of p40 Phox (binds PtdIns(3)P); FAPP1-PH, PH domain of FAPP1 (binds PtdIns(4)P); $P L C \delta$ - $P H$, PH domains of phospholipase C $\delta$ (binds PtdIns $(4,5) \mathrm{P}_{2}$ ); and GST alone as negative control, were incubated with PIP-strips ${ }^{\mathrm{TM}}$ as described (28) or used in liposome pull-down assays as described under "Materials and Methods." $10 \mathrm{~mm}$ EDTA was added for the zinc chelation experiment. Labeled PtdInsPs indicate the strongest interactions on each lipid blot.

nus ending at amino acids 520, 509, and 474 (aa 414-520, 414-509, and 414-474, respectively) were tested for PtdInsP binding. As shown in Fig. $6 A$, the most extensive truncation (aa 414-474), which eliminates the last two zinc-coordinating residues and almost certainly prevents the PHD finger from folding, not surprisingly fails to bind to $\operatorname{PtdIns}(4,5) \mathrm{P}_{2}$. Both the 414-509 and 414-520 truncations, which do not infringe on the core PHD finger sequence, also severely disrupt PtdInsP binding (Fig. 6A). However, the PtdInsP binding activity is not contained at the very $\mathrm{C}$ terminus, as a construct containing only the last 7 residues of RAG2 (aa 520-527) fails to bind (Fig. $6 A$ ). Thus, the last 7 amino acids of RAG2 are necessary but not sufficient for recognition of PtdInsPs. In this regard, within this region there are two basic residues; however, mutagenesis of these residues to alanines (R523A and R524A, named $\left.2 \mathrm{RA}_{(\mathrm{PHD}-\mathrm{CT})}\right)$ leads only to a very slight reduction in binding (Fig. 6A)

Analysis of the recombination activity of the truncation mutants is shown in Fig. 6C. The 4747 construct (aa 1-474 of RAG2) had little detectable recombination activity; however, the expression level of this protein is extremely low (Fig. 6E), suggesting that truncation midway through the PHD finger severely compromises stability of the entire protein. Next, we examined constructs 520 (aa 1-520 of RAG2) and 2RA (fulllength RAG2 with substitutions R523A and R524A). The 2RA construct had slightly reduced activity relative to WT (Fig. $6 C$ ). The 520 construct displayed robust recombination activity, forming coding and signal joints at levels 2-3 times higher than WT (Fig. $6 C$ ). This increased activity might be attributable in part to greater stability of the 520 protein versus WT (Fig. $6 E$; 


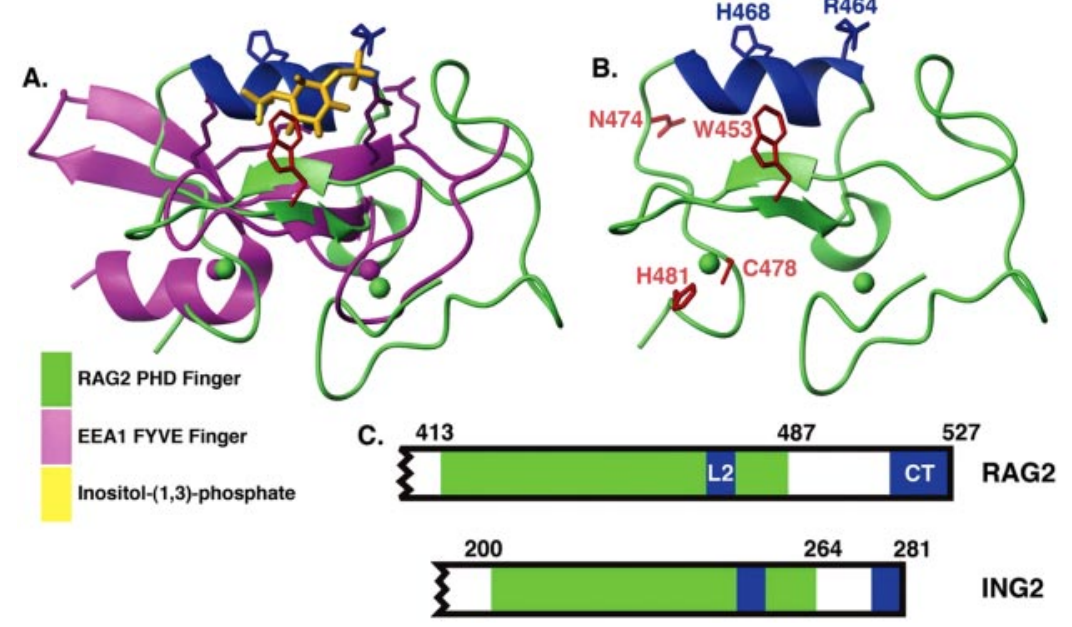

FIG. 4. Model of RAG2-PtdInsP interactions. A, structural overlay of the RAG2 PHD finger (green) on the EEA1 FYVE finger-IP(1,3) complex (FYVE domain, magenta; inositol 1,3- $\mathrm{P}_{2}$, yellow). (Protein Data Bank code $1 \mathrm{HYI}(46)$ ). The conserved $\beta$-sheet and zinc ions were used to overlay the two structures. Arginine side chains important for FYVE-PtdInsP binding are shown in magenta. Basic residues of RAG2 in the L2 segment (Arg-464 and His-468) are shown in blue. B, ribbon schematic of the RAG2 PHD finger structure with the indicated basic residues (blue) and disease-linked residues (red). C, schematic comparison of RAG2 and ING2 C termini. PHD fingers are shown in green. The blue boxes denote regions of positively charged residues important for PtdInsP binding by ING2. The analogous regions of RAG2 (L2 and CT) are also highlighted in blue, with the one inside the PHD finger (L2) corresponding to the blue $\alpha$-helix region in $B$.

FIG. 5. Functional analysis of RAG2 PHD finger disease-linked mutants. $A$, relative affinity of RAG2-PHD-CT for $\operatorname{PtdIns}(4,5) \mathrm{P}_{2}$. The indicated GST fusions were tested for binding to lipid blots containing serial dilutions of $\operatorname{PtdIns}(4,5) \mathrm{P}_{2}$ (in picomoles) as in Fig. $3 D$. B, effect on PtdInsP binding by disease-linked mutations. The indicated disease-linked mutations were introduced into the RAG2PHD-CT sequence (aa 414-527), and lipid blot assays were performed as in $A$. $A$ and $B$, representative data from at least three independent experiments are shown. $C$, effect of disease-linked mutations on $\mathrm{V}(\mathrm{D}) \mathrm{J}$ recombination. The indicated constructs were used for transient V(D)J recombination assays (see "Materials and Methods" $(39,40))$. Activity was normalized to WT activity, which was defined as $100 \%$. As negative controls, the activity of the coding joint (upper panel) and signal joint (lower panel) substrates in the absence of RAG1 and RAG2 (No RAGs) is shown. Results represent the mean \pm S.E. of at least three independent experiments. $D$, expression of RAG2 and disease-linked mutant proteins. Western analysis of M2 anti-FLAG immunoprecipitates from $293 \mathrm{~T}$ cells transfected with the indicated plasmids and probed with M5 anti-FLAG antibody to detect RAG2 proteins. Whole cell extracts were probed with anti-tubulin to control for loading.

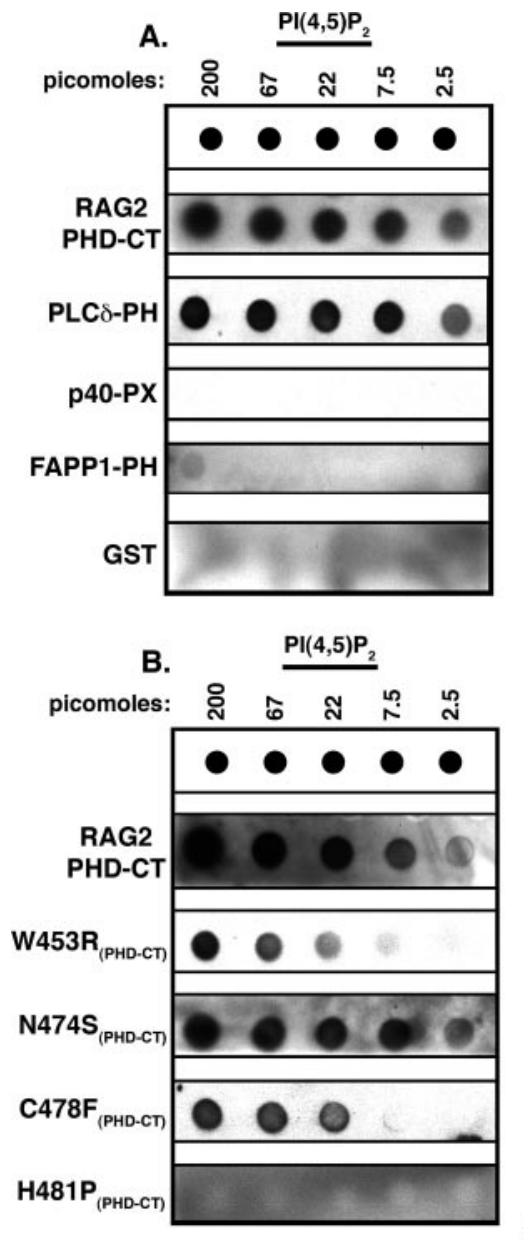

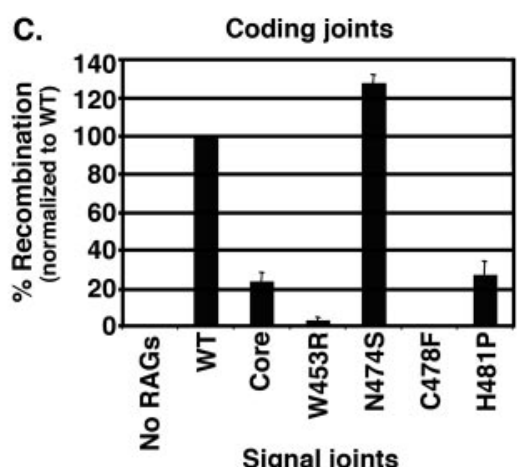
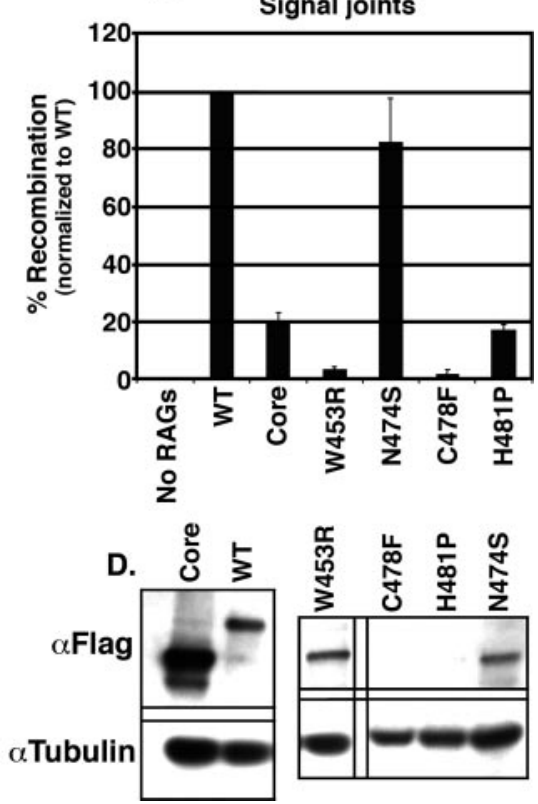

data not shown). Regardless, it is evident that disruption of PtdInsP binding does not affect V(D)J recombination on an exogenous substrate and in fact might facilitate this activity (see "Discussion").

Next, the role of the putative binding surface of the RAG2 PHD finger was investigated (see Fig. $4 B$, blue $\alpha$-helix). Sub- stitution of the two basic residues in this region with alanines (R464A and H468A, named $2 \mathrm{RH}_{(\mathrm{PHD}-\mathrm{CT})}$ ) led to a 10 -fold reduction in PtdIns $(4,5) \mathrm{P}_{2}$ binding (Fig. $6 B$ ). Analysis of the individual Arg-464 and His-468 mutations revealed an $\sim 5$-fold reduction in PtdIns $(4,5) \mathrm{P}_{2}$ binding for $\mathrm{R} 464 \mathrm{~A}_{(\mathrm{PHD}-\mathrm{CT})}$ relative to

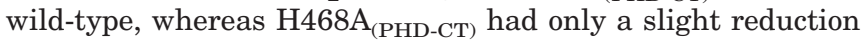


FIG. 6. Identification of residues critical for RAG2 PtdInsP binding and recombination activities. $A$, requirement of the very $\mathrm{C}$ terminus of RAG2 for PtdInsP binding. The indicated GST fusions were tested for binding to lipid blots as in Fig. 5A. 2RA, aa 414-527 with R523A and R524A substitutions. $B$, basic residues present on the L2 $\alpha$-helix are needed for efficient $\operatorname{PtdIns}(4,5) \mathrm{P}_{2}$ binding by RAG2. Experiments were performed as in $A$ using the indicated GST fusions. $2 R H$, aa $414-527$ with R464A and H468A substitutions; $2 R H / 2 R A$, aa $414-527$ with the $2 \mathrm{RH}$ and $2 \mathrm{RA}$ mutations; $2 R H / 520$, aa $414-520$ with $2 \mathrm{RH}$ mutations; W453R/520, aa 414-520 with W453R mutation. In both $A$ and $B$, representative data from at least three independent experiments is shown. $C$, effect of PtdInsP-binding mutants on V(D) J recombination. The indicated constructs were used to determine transient V(D)J recombination activity as in Fig. 5 C. Left panel, coding joints. Right panel, signal joints. $D$, role of Arg-464 and His-468 mutations alone in $\mathrm{V}(\mathrm{D}) \mathrm{J}$ recombination. The indicated constructs were used to determine transient $\mathrm{V}(\mathrm{D}) \mathrm{J}$ recombination activity as in C. Left panel, coding joints. Right panel, signal joints. $C$ and $D$, * denotes the average of two independent experiments; all other results represent the mean \pm S.E. from at least three independent experiments. $E$, expression of RAG2 and derivative proteins. Western analysis of RAG2 and derivative proteins are as described in Fig. $5 D$.
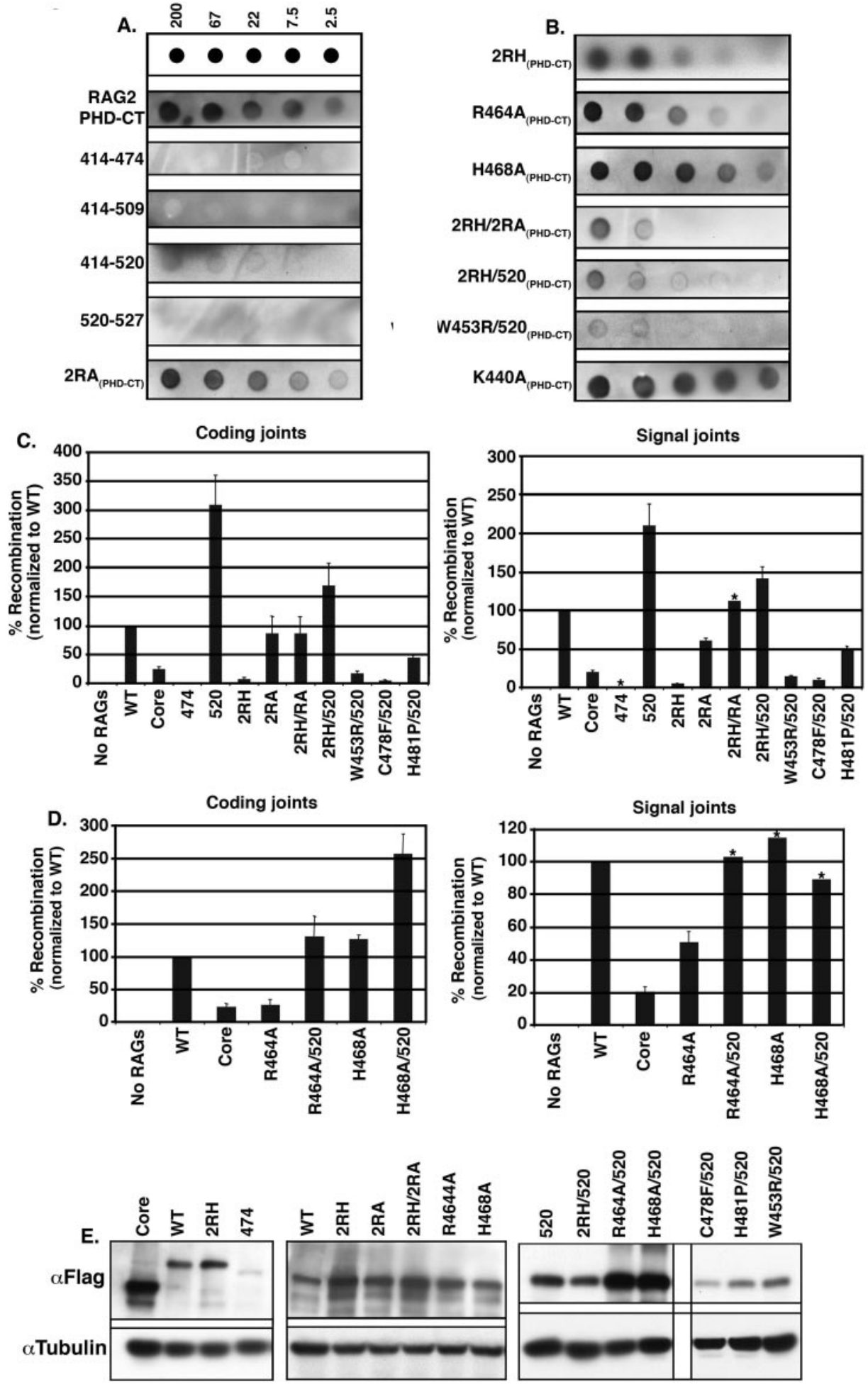

in binding (Fig. 6B). As a control, a basic residue located on the opposite face of the PHD finger from the $\alpha$-helix was mutated to alanine $\left(\mathrm{K}_{\left.440 \mathrm{~A}_{(\mathrm{PHD}-\mathrm{CT})}\right)}\right)$ and found to bind $\operatorname{PtdIns}(4,5) \mathrm{P}_{2}$ at wild-type levels (Fig. $6 B$ ). Thus, we conclude that Arg-464 and to a lesser extent His-468 participate in PtdInsP recognition.

Of note, the recombination activity of $2 \mathrm{RH}$ double mutants was severely compromised, forming coding and signal joints at only $\sim 5 \%$ of wild-type levels (Fig. $6 C$ ), suggesting that intermediate impairment of PtdInsP binding might correlate with decreased RAG2 function (see "Discussion"). The recombination defect in R464A single mutants is less severe than the double mutant (25 and 50\% relative to wild type for coding and signal joint formation, respectively), whereas the H468A mutant has no defect (Fig. 6D). These results are consistent with the role of the three lysines in the corresponding region of ING2; the severity of mutating all three cannot be explained by the additive contribution of the individual lysine residue (28).

To explore the relationship between the two PtdInsP-interacting segments of RAG2 (L2 and CT, Fig. 4C), single constructs containing mutations in both regions were tested for PtdInsP binding (Fig. 6B) and recombination activity (Fig. 6, $C$ and $D$ ). Binding to $\operatorname{PtdIns}(4,5) \mathrm{P}_{2}$ by the $2 \mathrm{RH}$ and $\mathrm{W} 453 \mathrm{R} \mathrm{mu}-$ tants in a 520 background was reduced $\sim 5$-fold relative to these mutations alone (Figs. $5 B$ and $6 B$, compare $2 \mathrm{RH} / 520_{\text {(PHD-CT) }}$ 
and $\mathrm{W} 453 \mathrm{R} / 520_{\text {(PHD-CT) }}$ to $2 \mathrm{RH}_{\text {(PHD-CT) }}$ and $\mathrm{W} 453 \mathrm{R}_{\text {(PHD-CT) }}$ ). Notably, combining the $2 \mathrm{RH}$ mutations with the $2 \mathrm{RA}$ mutations $\left(2 \mathrm{RH} / 2 \mathrm{RA}_{(\mathrm{PHD}-\mathrm{CT})}\right)$ had a similar effect (Fig. $\left.6 B\right)$, suggesting that the 2RA substitution behaves similarly to the 520 truncation with respect to altering the PtdInsP-binding phenotype of the $2 \mathrm{RH}$ mutant, despite having little effect on its own (Fig. 6, $A$ and $B$ ). One possible explanation for these data is that a physical interaction, potentially involving bridging by PtdInsPs, occurs between the L2 and CT regions of RAG2 (see "Discussion").

Based on these data, we hypothesized that the 520 and 2RA mutations might rescue the $2 \mathrm{RH}$ mutant recombination phenotype. Indeed combining the 520 or $2 \mathrm{RA}$ mutations with $2 \mathrm{RH}$ restores coding and signal joint formation back to WT levels (Fig. 6C). Similarly, the 520 and 2RA mutations rescued the single R464A mutation (Fig. 6D). Protein expression and nuclear localization were similar irrespective of the combination of mutations (Fig. $6 E$; data not shown). In contrast to $2 \mathrm{RH}$, the disease mutants (W453R, C478F, and H481P) had only slightly elevated activity in a 520 background (W453R/520, C478F/520, and $H 481 P / 520$, Fig. $6 C$ ). Again, these proteins all expressed and localized to the nucleus, although C478F/520 and H481P/ 520 expressed poorly, likely a result of PHD finger misfolding (Fig. 6E; data not shown). Based on these data, we suggest that RAG2 PHD finger mutant derivatives fall into one of three phenotypic classes displaying the following: (i) WT levels of PtdInsP binding and recombination activity; (ii) little or no PtdInsP binding and normal to hyper-recombination activity (with the exception of mutants that prevent formation of the PHD finger structure and hence destabilize RAG2); and (iii) intermediate PtdInsP binding (between class I and II) and defective recombination activity in cell culture.

Role of the PHD Finger in $V(D) J$ Cleavage in Vitro-It is possible that the third class of mutations structurally destabilize the RAG2 protein, explaining the low recombination activity. Comparison of the ${ }^{15} \mathrm{~N}$ HSQC spectra from ${ }^{15} \mathrm{~N}$-labeled samples of wild-type and mutant proteins revealed significant peak shifts localized only to the immediate vicinity of the mutation site (data not shown), indicating that the PHD finger is not misfolded. To rule out an effect on the overall stability of full-length RAG2 protein and to ask whether the class III defects were affecting the DNA cleavage reaction itself versus a different step of V(D)J recombination, recombinant WT and mutant proteins were tested in an in vitro assay for cleavage at a single recombination signal sequences site. As shown in Fig. $7 A, 2 \mathrm{RH}$ and W453R both cleave substrate at the level of wild-type RAG2. Core, 520, and 520 derivatives all cleave at comparable levels to one another, and do so at a substantially higher level than WT and WT derivatives (Fig. 7A). This difference is likely a manifestation of the increased stability of core and 520 proteins, which results in higher specific activity (Fig. 6E; data not shown). Regardless, these data demonstrate that reduction or elimination of PtdInsP binding does not impact upon RAG2 cleavage activity. Moreover, these data indicate that $2 \mathrm{RH}$ and Trp- 453 are enzymatically viable, properly folded proteins, arguing that their defect in the transient assay is a consequence of a step distinct from DNA cleavage (see "Discussion").

Regulation of in Vitro Transposition by the RAG2 PHD Finger-It has been shown previously that the $\mathrm{C}$ terminus of RAG2 prevents transposition, an activity that might be important for avoiding unwanted genomic instability in developing lymphocytes (11-13). To assess the role of the PHD finger in repressing transposition, we tested in vitro the ability of RAG2 and its derivatives to transpose signal ends starting from either intact or precleaved substrates into an unrelated plasmid

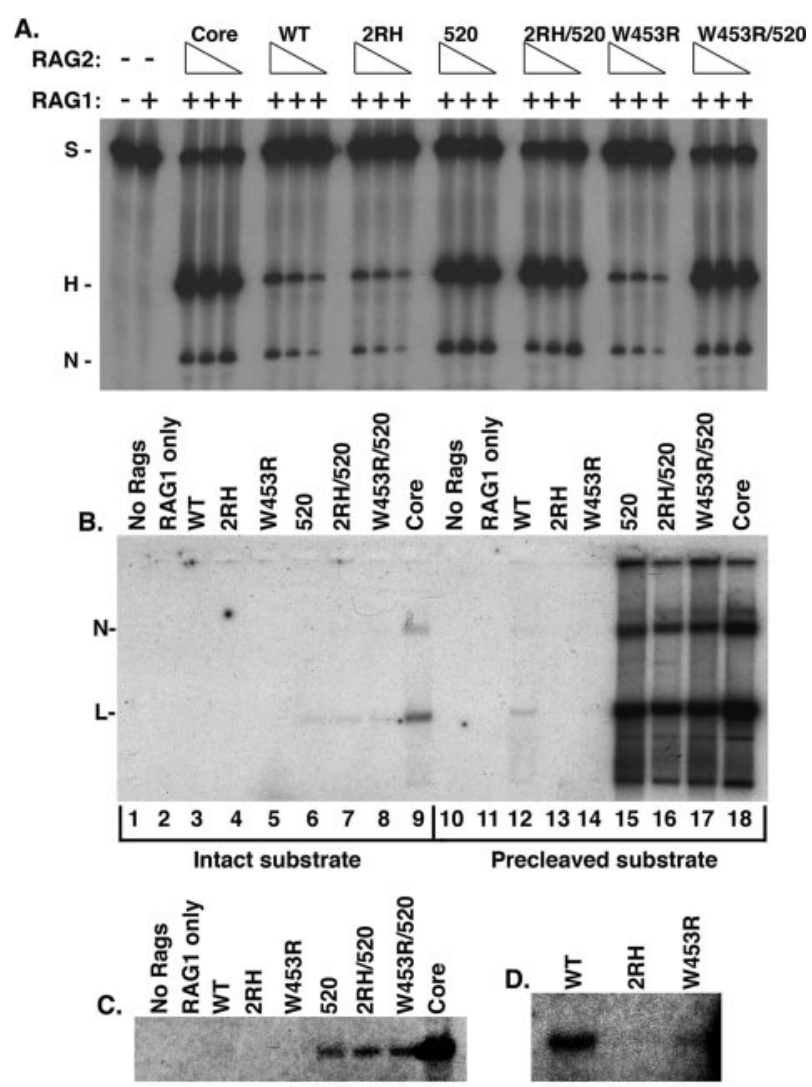

FIG. 7. RAG2 PHD finger mutants do not disrupt cleavage activity but do affect transposition in vitro. $A$, PtdInsP-binding mutations do not affect the in vitro cleavage activity of RAG2. Serial dilutions of the indicated recombinant proteins were used for in vitro cleavage assays as described previously (11). The positions of the substrate $(S)$ and cleavage products (hairpin $(H)$ and nick $(N)$ ) are indicated. A representative gel from at least three independent experiments is shown. $B$, PtdInsP-binding mutants affect in vitro transposition. The indicated recombinant proteins were tested for their ability to transpose either an intact or precleaved V(D)J recombination substrate into an unrelated plasmid. $N$, nicked plasmid, the result of a single transposition event. $L$, linearized plasmid, the result of two transposition events, one into each strand. $C$, darker exposure of gel in $B$, lanes 1-9. $D$, darker exposure of the gel in $B$, lanes 12-14.

(Fig. 7B) (11). On an intact substrate, the transposition event requires the following four steps: (i) cleavage of substrate; (ii) release of the coding ends; (iii) capture of the plasmid target; and (iv) joining of the cleaved signal ends to the plasmid target. The use of a precleaved substrate bypasses the cleavage and release steps, allowing for direct examination of the capture and joining reaction steps (49).

Consistent with previous reports, the Core protein exhibited transposition activity on an intact substrate, whereas WT (and its derivatives) did not (Fig. 7, $B$ and $C$ ) (11). The 520, W453R/ 520 , and $2 \mathrm{RH} / 520$ proteins had considerably less activity than Core but, nonetheless, still carry out the reaction (Fig. 7, $B$ and $C$ ). This might be due to a portion of the inhibitory activity contained within the $\mathrm{C}$ terminus being dependent on the last seven amino acids, be a manifestation of the high specific activity of these proteins, or both. As observed previously, wild-type RAG2, although unable to support transposition on an intact substrate, is able to carry out transposition on a precleaved substrate (Fig. 7) $(11,50)$. In contrast, the $2 \mathrm{RH}$ and W453R mutants, which cleave in vitro at levels similar to wild type (Fig. 7A), are compromised in their ability to transpose a precleaved substrate (Fig. 7, $B$ and $D$ ). W453R exhibits a very low level of transposition relative to WT, and transposition by $2 \mathrm{RH}$ is not detected (Fig. $7 D$ ). These data suggest that a func- 
tional PHD finger is required during transposition for either target capture, or joining, or both steps. This requirement, however, is bypassed by combining the W453R and $2 \mathrm{RH}$ mutations with deletion of the last seven amino acids of RAG2, as on a precleaved substrate, $520,2 \mathrm{RH} / 520, \mathrm{~W} 453 \mathrm{R} / 520$, and Core all display a similar level of activity, which is commensurate with their cleavage activities (Fig. 7B).

\section{DISCUSSION}

The C Terminus of RAG2 Contains a PHD Finger-We have presented here the first structural data on RAG2, demonstrating that a region within the non-core $\mathrm{C}$ terminus of the protein contains a noncanonical PHD finger (Fig. 1). This finding is in agreement with a study that drew similar conclusions based upon the primary sequence of RAG2 (21). The presence of a PHD finger within RAG2 is consistent with PHD fingers being commonly found on chromatin-associated proteins (22) and with regulation of recombination being fundamentally linked to chromatin structure (reviewed in Ref. 51).

PHD fingers are recognized as clinically important motifs, as mutations within PHD fingers are implicated in tumorigenesis, autoimmune disorders, and other genetic diseases $(23,52,53)$. Here we have shown that the four distinct homozygous point mutations found outside of the core region of RAG2 and identified in patients suffering from SCID and OS all fall within the PHD finger of RAG2 (Fig. 4B). Two of these residues, Cys-478 and His-481, are zinc-coordinating residues and are expected to disrupt the PHD finger fold. The other two residues, Trp-453 and Asn-474, are positioned to influence the surface $\alpha$-helix formed by the L2 segment of the RAG2 PHD finger that participates in interactions with PtdInsPs (Fig. 6). Other examples of disease-related PHD finger mutations located in the vicinity of this L2 surface include a G132N substitution in the ATRX protein implicated in X-linked mental retardation syndrome and a P328L substitution in the AIRE-1 protein implicated in the development of the autoimmune disorder APECED $(52,53)$. Finally, a basic patch composed of three lysine residues within the analogous segment of the PHD fingers of ING1, ING2, and $\mathrm{ACF}$ is required for the PtdInsP binding activity of these motifs (28). We therefore postulate that this surface might be generally utilized as a critical determinant for specifying the binding partners and functions for diverse PHD fingers.

RAG2-PtdInsP Interactions-Recently, the PHD finger of ING2 and a number of other nuclear proteins containing PHD fingers were found to interact with mono-phosphorylated PtdInsPs (28). Our data show that the PHD finger of RAG2 also binds to PtdInsPs, with a preference for bis-phosphorylated PtdInsP species (Fig. 3). Despite this difference in specificity, the architecture governing the interactions is quite similar. In order for PtdInsP binding to occur, the RAG2 PHD finger, like other PHD fingers, requires a basic patch between the 6th and 7th zinc-coordinating residues (L2 segment) and a stretch of basic amino acids immediately C-terminal to the PHD finger motif (Fig. 6). This phosphoinositide-binding mode is reminiscent of the mechanism used by the ENTH domain of Epsin to recognize PtdIns $(4,5) \mathrm{P}_{2}$, where residues from the core ENTH domain and residues from the otherwise unstructured N-terminal region are both required for phosphoinositide binding (54). In the ENTH-PtdIns $(4,5) \mathrm{P}_{2}$ complex, the unstructured region folds into a functionally important $\alpha$-helix (55). We speculate that the C-terminal region of RAG2 normally exists in a relatively unstructured state, but during binding to PtdInsPs it folds over to make contact with the basic surface within the L2 region of the PHD finger so that both segments directly contribute to PtdInsP recognition.

PtdInsPs modulate cellular signaling pathways by regulating the temporal and spatial localization and conformation of their target protein receptors (56). By these mechanisms, PtdInsPs can create microenvironments that serve to increase the probability of high affinity interactions occurring between two proteins and/or molecular complexes. Recombination requires exquisite temporal and spatial regulation, which we postulate might in part be achieved via PtdInsPs and PtdInsPRAG2 interactions. In this regard, $\operatorname{PtdIns}(4,5) \mathrm{P}_{2}$ has been clearly shown to be present and active within the nucleus and at chromatin (reviewed in Ref. 57), consistent with the notion that it might regulate recombination via interactions with the PHD finger of RAG2. However, until now, all PtdInsP species with the exception of $\operatorname{PtdIns}(3,5) \mathrm{P}_{2}$ have been shown to be present in the nucleus, and a different PtdInsP species might be regulating RAG2 (see Fig. 3, $A$ and $B$ ) (58). Allosteric modification of RAG2 by PtdInsPs is unlikely to regulate cleavage as the $2 \mathrm{RH}$ and 520 mutants are able to cut in vitro (Fig. $7 \mathrm{~A}$ ), and PtdIns $(4,5) \mathrm{P}_{2}$-enriched liposomes did not have a clear effect on RAG2 in vitro cleavage activity (data not shown). However, it is possible that such effects will only be observed within a more physiological environment. An alternative and not mutually exclusive possibility is that PtdInsPs play a role in regulating the localization of RAG2 during the course of the recombination reaction. Experiments aimed at specifically altering in vivo nuclear PtdInsP levels will begin to address these questions (59).

Inositol polyphosphates (IPs) are signaling molecules with clearly established functions in the nucleus (reviewed in Ref. 60). In addition, IPs have been shown to regulate nonhomologous end joining by binding to Ku70/80, suggestive of a potential intriguing link to RAG2 and V(D)J recombination $(61,62)$. We have not detected an interaction between RAG2 and inositol 1,4,5-triphosphate or inositol 1,4-bisphosphate, but we have not tested higher phosphorylated forms (data not shown). Potential functional interactions between RAG2 and IPs and/or PtdInsPs might best be assayed in Saccharomyces cerevisiae, using a recently established RAG-dependent recombination system (63).

The Role of the PHD Finger in $V(D) J$ Recombination-We have found that mutations that target the functions or structural integrity of the RAG2 PHD finger display a more severe recombination defect than the Core protein, which lacks the PHD finger (Figs. $5 C$ and $6 C$ ). Highlighting this difference, we show that mutating two basic residues on the face of the PHD finger $(2 \mathrm{RH})$, although not disrupting the structural integrity of the motif or the enzymatic activity of purified RAG2, severely compromises recombination on an exogenous substrate (Figs. $6 C$ and 7A). This phenotype can be entirely reversed by combining the $2 \mathrm{RH}$ mutation with deletion or mutation of the last seven amino acids of RAG2 (Fig. 6C). Moreover, deletion of the last seven amino acids restores the ability of both W453R and $2 \mathrm{RH}$ to transpose a precleaved substrate (Fig. $7 B$ ). Based on these data we hypothesize that a functional, and possibly physical, interaction takes place between the L2 segment of the RAG2 PHD finger and the very C terminus of RAG2, a proposal further supported by the PtdInsP binding data (Figs. $5 B$ and Fig. 6, $A$ and $B$ ). One model to explain these data is that the PHD finger adopts two distinct states, one permissive for recombination and a second inhibitory. Consistent with this idea, changes in buffer $\mathrm{pH}$ or high PtdInsP concentrations lead to a small set of peak shifts in the HSQC spectra within the L2 segment of the RAG2 PHD finger, suggesting that the domain is not structurally static (data not shown). We speculate that binding of the PHD finger to a molecular partner, such as PtdInsPs, might modify the equilibrium between these two states. In this context, mutations that eliminate PtdInsP binding, such as the 520 truncation, shift the equilibrium to the permissive state. In contrast, mutations in the PHD finger that 
partially impair PtdInsP binding might adopt a conformation that mimics the bound state and shift the equilibrium toward the inhibitory state. Combining the $2 \mathrm{RH}$ mutant with the 520 or the 2RA generates null PtdInsP binders, shifting the equilibrium back toward the permissive state. A similar regulatory mechanism is observed for vinculin and N-WASP, in which PtdIns $(4,5) \mathrm{P}_{2}$ binding shifts the equilibrium between the active and inactive states of these proteins $(64,65)$. In the case of $\mathrm{N}$-WASP, binding to $\operatorname{PtdIns}(4,5) \mathrm{P}_{2}$ is highly cooperative so that homeostatic levels of $\operatorname{PtdIns}(4,5) \mathrm{P}_{2}$ do not alter the activity of the protein, and N-WASP is activated only in response to signal-induced changes in $\operatorname{PtdIns}(4,5) \mathrm{P}_{2}$ density (65). The observation that the PHD-CT segment of RAG2 alone binds with greater specificity to $\mathrm{PtdIns}(4,5) \mathrm{P}_{2}$ (relative to other PtdInsPspecies) in the context of the molecule being enriched and presented within polymerized liposomes (Fig. $3 E$ ) argues that the interaction between RAG2 and $\operatorname{PtdIns}(4,5) \mathrm{P}_{2}$ (or possibly a different PtdInsP-species) might be cooperative as well $(45,66)$. This suggests that signal-induced changes of $\operatorname{PtdIns}(4,5) \mathrm{P}_{2}$ levels at chromatin might act as a sensitive switch to regulate recombination.

Gene targeted replacement of full-length RAG2 by Core leads to selective defects in V-to-DJ rearrangement, which can be reversed in cell lines by overexpression of the non-core region $(9,10)$. In this study, we observe that the $2 \mathrm{RH}$ and W453R mutants are deficient in the target capture/joining steps of transposition, suggestive of a physiologic regulatory role for the PHD finger during the joining phase of $\mathrm{V}(\mathrm{D}) \mathrm{J}$ recombination. In this regard, the defective V-to-DJ recombination phenotype observed with the Core RAG2 mice might be due specifically to the absence of the PHD finger. In vivo confirmation of this hypothesis will require targeted mutagenesis of the endogenous RAG2 locus for analysis of V(D)J recombination and lymphocyte development. Here we have provided the first structural analysis of the RAG2 protein, demonstrating the presence of a PHD finger motif in the $\mathrm{C}$ terminus of RAG2, and we presented evidence that the RAG2 PHD finger, despite being outside of the core domain, plays a fundamental physiologic role in $\mathrm{V}(\mathrm{D}) \mathrm{J}$ recombination.

\section{REFERENCES}

1. Schatz, D. G., Oettinger, M. A., and Baltimore, D. (1989) Cell 59, 1035-1048 2. Oettinger, M. A., Schatz, D. G., Gorka, C., and Baltimore, D. (1990) Science 248, 1517-1523

3. Gellert, M. (2002) Annu. Rev. Biochem. 71, 101-132

4. Jung, D., and Alt, F. W. (2004) Cell 116, 299-311

5. O'Driscoll, M., and Jeggo, P. (2002) Mutat. Res. 509, 109-126

6. Sadofsky, M. J., Hesse, J. E., and Gellert, M. (1994) Nucleic Acids Res. 22, 1805-1809

7. Cuomo, C. A., and Oettinger, M. A. (1994) Nucleic Acids Res. 22, 1810-1814

8. McBlane, J. F., van Gent, D. C., Ramsden, D. A., Romeo, C., Cuomo, C. A. Gellert, M., and Oettinger, M. A. (1995) Cell 83, 387-395

9. Liang, H.-E., Hsu, L.-Y., Cado, D., Cowell, L. G., Kelsoe, G., and Schlissel, M. S. (2002) Immunity 17, 639-651

10. Akamatsu, Y., Monroe, R., Dudley, D. D., Elkin, S. K., Gartner, F., Talukder S. R., Takahama, Y., Alt, F. W., Bassing, C. H., and Oettinger, M. A. (2003) Proc. Natl. Acad. Sci. U. S. A. 100, 1209-1214

11. Elkin, S. K., Matthews, A. G., and Oettinger, M. A. (2003) EMBO J. 22, 1931-1938

12. Tsai, C. L., and Schatz, D. G. (2003) EMBO J. 22, 1922-1930

13. Swanson, P. C., Volkmer, D., and Wang, L. (2004) J. Biol. Chem. 279 4034-4044

14. Sekiguchi, J. A., Whitlow, S., and Alt, F. W. (2001) Mol. Cell 8, 1383-1390

15. Schwarz, K., Gauss, G. H., Ludwig, L., Pannicke, U., Li, Z., Lindner, D. Friedrich, W., Seger, R. A., Hansen-Hagge, T. E., Desiderio, S., Lieber, M. R., and Bartram, C. R. (1996) Science 274, 97-99

16. Gomez, C. A., Ptaszek, L. M., Villa, A., Bozzi, F., Sobacchi, C., Brooks, E. G., Notarangelo, L. D., Spanopoulou, E., Pan, Z. Q., Vezzoni, P., Cortes, P., and Santagata, S. (2000) Mol. Cell. Biol. 20, 5653-5664

17. Villa, A., Sobacchi, C., Notarangelo, L. D., Bozzi, F., Abinun, M., Abrahamsen, T. G., Arkwright, P. D., Baniyash, M., Brooks, E. G., Conley, M. E., Cortes, P., Duse, M., Fasth, A., Filipovich, A. M., Infante, A. J., Jones, A., Mazzolari, E., Muller, S. M., Pasic, S., Rechavi, G., Sacco, M. G., Santagata, S., Schroeder, M. L., Seger, R., Strina, D., Ugazio, A., Valiaho, J., Vihinen, M., Vogler, L. B., Ochs, H., Vezzoni, P., Friedrich, W., and Schwarz, K. (2001) Blood 97, 81-88
18. Noordzij, J. G., de Bruin-Versteeg, S., Verkaik, N. S., Vossen, J. M., de Groot, R., Bernatowska, E., Langerak, A. W., van Gent, D. C., and van Dongen, J. J. (2002) Blood 100, 2145-2152

19. Corneo, B., Benmerah, A., and Villartay, J. P. (2002) Eur. J. Immunol. 32, 2068-2073

20. Ross, A. E., Vuica, M., and Desiderio, S. (2003) Mol. Cell. Biol. 23, 5308-5319 21. Callebaut, I., and Mornon, J. P. (1998) Cell. Mol. Life Sci. 54, 880-891

22. Sutherland, H. G., Mumford, G. K., Newton, K., Ford, L. V., Farrall, R., Dellaire, G., Caceres, J. F., and Bickmore, W. A. (2001) Hum. Mol. Genet. 10, 1995-2011

23. Pascual, J., Martinez-Yamout, M., Dyson, H. J., and Wright, P. E. (2000) J. Mol. Biol. 304, 723-729

24. Capili, A. D., Schultz, D. C., Rauscher, I. F., and Borden, K. L. (2001) EMBO J. 20, 165-177

25. Stenmark, H., Aasland, R., and Driscoll, P. C. (2002) FEBS Lett. 513, 77-84

26. Fang, S., Lorick, K. L., Jensen, J. P., and Weissman, A. M. (2003) Semin Cancer Biol. 13, 5-14

27. Coscoy, L., and Ganem, D. (2003) Trends Cell Biol. 13, 7-12

28. Gozani, O., Karuman, P., Jones, D. R., Ivanov, D., Cha, J., Lugovskoy, A. A., Baird, C. L., Zhu, H., Field, S. J., Lessnick, S. L., Villasenor, J., Mehrotra, B., Chen, J., Rao, V. R., Brugge, J. S., Ferguson, C. G., Payrastre, B., Myszka, D. G., Cantley, L. C., Wagner, G., Divecha, N., Prestwich, G. D., and Yuan, J. (2003) Cell 114, 99-111

29. Aravind, L., Iyer, L. M., and Koonin, E. V. (2003) Cell Cycle 2, 123-126

30. Scheel, H., and Hofmann, K. (2003) Trends Cell Biol. 13, 285-288

31. Ragvin, A., Valvatne, H., Erdal, S., Arskog, V., Tufteland, K. R., Breen, K., Am, O. Y., Eberharter, A., Gibson, T. J., Becker, P. B., and Aasland, R. (2004) J. Mol. Biol. 337, 773-788

32. Eberharter, A., Vetter, I., Ferreira, R., and Becker, P. B. (2004) EMBO J. 23 4029-4039

33. Hyberts, S. G., and Wagner, G. (2003) J. Biomol. NMR 26, 335-344

34. Delaglio, F., Grzesiek, S., Vuister, G. W., Zhu, G., Pfeifer, J., and Bax, A. (1995) J. Biomol. NMR 6, 277-293

35. Guntert, P., Mumenthaler, C., and Wuthrich, K. (1997) J. Mol. Biol. 273, 283-298

36. Schwieters, C. D., Kuszewski, J. J., Tjandra, N., and Marius Clore, G. (2003) J. Magn Reson, 160, 65-73

37. Patki, V., Virbasius, J., Lane, W. S., Toh, B. H., Shpetner, H. S., and Corvera S. (1997) Proc. Natl. Acad. Sci. U. S. A. 94, 7326-7330

38. Dai, Y., Kysela, B., Hanakahi, L. A., Manolis, K., Riballo, E., Stumm, M. Harville, T. O., West, S. C., Oettinger, M. A., and Jeggo, P. A. (2003) Proc. Natl. Acad. Sci. U. S. A. 100, 2462-2467

39. Gauss, G. H., and Lieber, M. R. (1993) Mol. Cell. Biol. 13, 3900-3906

40. Gauss, G. H., and Lieber, M. R. (1996) Mol. Cell. Biol. 16, 258-269

41. Misra, S., and Hurley, J. H. (1999) Cell 97, 657-666

42. Kutateladze, T. G., Ogburn, K. D., Watson, W. T., de Beer, T., Emr, S. D., Burd, C. G., and Overduin, M. (1999) Mol. Cell 3, 805-811

43. Zheng, N., Wang, P., Jeffrey, P. D., and Pavletich, N. P. (2000) Cell 102, 533-539

44. Kwan, A. H., Gell, D. A., Verger, A., Crossley, M., Matthews, J. M., and Mackay, J. P. (2003) Structure (Camb.) 11, 803-813

45. Ferguson, C. G., James, R. D., Bigman, C. S., Sheppard, D. A., Abdiche, Y., David, G. M., and Prestwich, G. D. (2005) Submitted

46. Kutateladze, T., and Overduin, M. (2001) Science 291, 1793-1796

47. DiNitto, J. P., Cronin, T. C., and Lambright, D. G. (2003) Sci. STKE 2003, RE16

48. Steen, S. B., Han, J. O., Mundy, C., Oettinger, M. A., and Roth, D. B. (1999) Mol. Cell. Biol. 19, 3010-3017

49. Matthews, A. G., Elkin, S. K., and Oettinger, M. A. (2004) EMBO J. 23, 1198-1206

50. Jiang, H., Ross, A. E., and Desiderio, S. (2004) J. Biol. Chem. 279, 8478-8486

51. Schlissel, M. (2004) Nat. Genet. 36, 438-440

52. Gibbons, R. J., Bachoo, S., Picketts, D. J., Aftimos, S., Asenbauer, B., Bergoffen, J., Berry, S. A., Dahl, N., Fryer, A., Keppler, K., Kurosawa, K., Levin, M. L., Masuno, M., Neri, G., Pierpont, M. E., Slaney, S. F., and Higgs, D. R. (1997) Nat. Genet. 17, 146-148

53. Saugier-Veber, P., Drouot, N., Wolf, L. M., Kuhn, J. M., Frebourg, T., and Lefebvre, H. (2001) Eur. J. Endocrinol. 144, 347-351

54. Itoh, T., Koshiba, S., Kigawa, T., Kikuchi, A., Yokoyama, S., and Takenawa, T. (2001) Science 291, 1047-1051

55. Ford, M. G., Mills, I. G., Peter, B. J., Vallis, Y., Praefcke, G. J., Evans, P. R., and McMahon, H. T. (2002) Nature 419, 361-366

56. Payrastre, B., Missy, K., Giuriato, S., Bodin, S., Plantavid, M., and Gratacap, M. (2001) Cell. Signal. 13, 377-387

57. Martelli, A. M., Manzoli, L., and Cocco, L. (2004) Pharmacol. Ther. 101, 47-64

58. Cocco, L., Maraldi, N. M., and Manzoli, F. A. (2004) Eur. J. Histochem. 48, $83-88$

59. Hama, H., Torabinejad, J., Prestwich, G. D., and DeWald, D. B. (2004) Methods Mol. Biol. 284, 243-258

60. York, J. D., Guo, S., Odom, A. R., Spiegelberg, B. D., and Stolz, L. E. (2001) Adv. Enzyme Regul. 41, 57-71

61. Ma, Y., and Lieber, M. R. (2002) J. Biol. Chem. 277, 10756-10759

62. Hanakahi, L. A., and West, S. C. (2002) EMBO J. 21, 2038-2044

63. Clatworthy, A. E., Valencia, M. A., Haber, J. E., and Oettinger, M. A. (2003) Mol. Cell 12, 489-499

64. Bakolitsa, C., Cohen, D. M., Bankston, L. A., Bobkov, A. A., Cadwell, G. W., Jennings, L., Critchley, D. R., Craig, S. W., and Liddington, R. C. (2004) Nature 430, 583-586

65. Papayannopoulos, V., Co, C., Prehoda, K. E., Snapper, S., Taunton, J., and Lim, W. A. (2005) Mol. Cell 17, 181-191

66. Prestwich, G. D. (2004) Chem. Biol. 11, 619-637 
A PHD Finger Motif in the C Terminus of RAG2 Modulates Recombination Activity Sheryl K. Elkin, Dmitri Ivanov, Mark Ewalt, Colin G. Ferguson, Sven G. Hyberts, Zhen-Yu J. Sun, Glenn D. Prestwich, Junying Yuan, Gerhard Wagner, Marjorie A. Oettinger and Or P. Gozani

J. Biol. Chem. 2005, 280:28701-28710.

doi: 10.1074/jbc.M504731200 originally published online June 17, 2005

Access the most updated version of this article at doi: 10.1074/jbc.M504731200

Alerts:

- When this article is cited

- When a correction for this article is posted

Click here to choose from all of JBC's e-mail alerts

Supplemental material:

http://www.jbc.org/content/suppl/2005/06/28/M504731200.DC1

This article cites 64 references, 22 of which can be accessed free at http://www.jbc.org/content/280/31/28701.full.html\#ref-list-1 